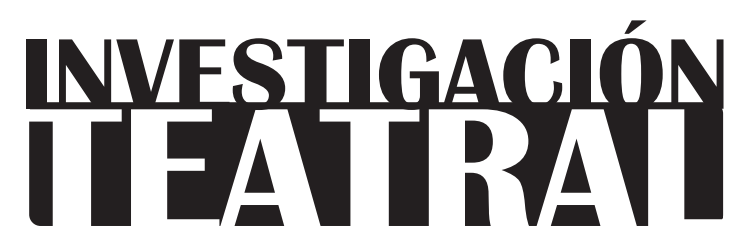

Revista de artes escénicas y performatividad

Vol. 11, Núm. 18

octubre 2020-marzo 2021

Segunda época

ISSN impreso: 1665-8728

ISSN electrónico: 2594-0953

Universidad Veracruzana

\title{
La comunicación entre actor y espectador: una aproximación al psicoanálisis
}

\author{
Iván Zúñiga Vargas*
}

\footnotetext{
* Investigador independiente, México. e-mail:ivansellama@outlook.com
}

Recibido: 15 de enero de 2020

Aceptado: 06 de julio de 2020

Doi: https://doi.org/10.25009/it.v11i18.2656 


\title{
La comunicación entre actor y espectador: una aproximación al psicoanálisis
}

\section{Resumen}

Este artículo se plantea una búsqueda de los vínculos que surgen entre actor, espectador y público en base a los escritos de Luisa Josefina Hernández en torno a un teatro trágico desde la perspectiva aristotélica, un teatro que nos lleva a desentrañar lo más sublime y lo más oscuro de nosotros mismos. A partir de la confrontación de la fórmula básica del código teatral de Erika Fischer-Lichte y las teorías de Lacan sobre el inconsciente, se propone un modelo de la comunicación en el teatro con el fin de evidenciar la complejidad psíquica del fenómeno escénico.

Palabras clave: teatro; representación; neurosis; poética; Aristóteles.

\section{The Communication Between Actor and Spectator: a Psychoanalytical Approach}

\begin{abstract}
This article addresses how theatrical communication takes place between performers and spectators, seeking the links that are established between them. The author picks up Luisa Josefina Hernández's vision of a tragic theater from the Aristotelian perspective, a theatre that leads us to unravel the most sublime and the darkest in ourselves. Starting from the confrontation of the basic formula of Erika Fischer-Lichte's theatrical code and Jacques Lacan's theories about the unconscious, the author proposes a model of communication in theater that demonstrates the psychic complexity of the phenomenon.
\end{abstract}

Keywords: Theater; representation; neurosis; poetics; Aristotle. 


\section{La comunicación entre actor y espectador: una aproximación al psicoanálisis}

La contemplación apreciativa de una representación dramática cumple en el adulto la misma función que el juego desempeña en el niño, al satisfacer su perpetua esperanza de poder hacer cuanto los adultos hacen

(Freud 1).

\footnotetext{
I 1 teatro, en sus diferentes formas, constituye una actividad humana intrínsecamente - relacionada con la naturaleza psíquica del sujeto. Una relación que puede intuirse 1 -como planteó Aristóteles- en la capacidad nata de mimetizar y la predisposición al juego por parte del infante, tanto en la formación de sociedades como en la institución de roles y jerarquías. Mientras los procesos de adaptación de las artes en sus contextos se han complejizado, el teatro, que siempre está en crisis, se ha enfrentado en repetidas ocasiones a la sentencia de una inminente desaparición frente a las nuevas tecnologías y medios masivos de distribución de contenidos.

Ante esta situación han proliferado, por un lado, el teatro ligero y de entretenimiento simple: la comedia comercial moderna, la ausencia de acción, el discurso panfletario, etcétera; por otro lado, encontramos una variación llamada "conceptual" asociada a las formas posmodernas de hacer teatro, que van desde la mera exposición de ideas plásticas hasta la desintegración de la noción de sujeto.

Hasta cierto punto, en la escena mexicana aún se conserva un impulso de búsqueda, aunque cada vez hay menos interés por parte del público en presenciar obras que no pasen de la
} 
superficie, la anécdota simple o inmersa en el abismo de lo subjetivo, relativizando el propósito del teatro. Son contados los creadores que conservan una relación vital con la escena, que buscan el enlace con las pasiones, con lo sublime y lo oculto del espectador, a consciencia de que el único canal efectivo para ello es la implicación de quien encarna el discurso, el actor expuesto frente a sí y frente al otro, otro compañero, otro espectador, otro inconsciente.

Por ello la necesidad de voltear al origen (la tragedia griega) nos encuentra una y otra vez mientras buscamos una poética que mantenga al sujeto en todas sus facetas como la unidad mínima de donde surge y, a veces, hacia donde se dirige el teatro. El actor y el espectador constituyen los pilares del acontecimiento teatral, forman una comunión que ocurre en el teatro como en el psicoanálisis: el deseo es el deseo del otro, y, "desear el deseo del otro, supone colocarme a su servicio" (Asensi).

Este artículo considera los elementos imprescindibles en el acontecimiento teatral: ${ }^{1}$ el actor y el espectador. Partimos de una base clave, el surgimiento del drama vinculado a la capacidad humana de identificación con el otro y su efecto en el espectador, la catarsis aristotélica.

Para profundizar en ello, será indispensable recurrir al psicoanálisis y considerar los estudios previos de la relación entre actor y espectador desde distintas perspectivas. Este panorama nos ayudará a sustentar un modelo de comunicación en el acontecimiento teatral, colocando a los asistentes ${ }^{2}$ como punto central.

La relación entre actor y espectador ha sido mitificada durante generaciones de directores y actores empíricos, se encuentra rodeada de conceptos vagos como "magia" o "misticismo", que sólo sugieren que se trata de un fenómeno inexplicable cuya definición se encuentra fuera de alcance. Los trabajos de Otto Berdiel y Gustavo Geirola, que abordan la relación de la teatrología y el psicoanálisis, tanto en el ensayo teatral como en la creación de círculos de investigación en torno a estas disciplinas, aún no se han centrado en analizar específicamente el vínculo psíquico que se establece entre el actor y el espectador.

Partimos entonces de la relación ya explorada entre teatrología y psicoanálisis, para después aventurar un modelo de comunicación teatral con los conceptos recabados, tomando como punto de partida la concepción de catarsis en la Poética de Aristóteles desde la perspectiva de la dramaturga e investigadora mexicana Luisa Josefina Hernández, algunos de los conceptos incluidos en el "Grafo III" de Lacan, "El inconsciente", y la fórmula

1 Jorge Dubatti refiere con este término a la singularidad del teatro, donde el acontecimiento sucede en tres momentos: acontecimiento convivial, acontecimiento del lenguaje o poético, y acontecimiento de la constitución del espacio del espectador ("Cultura teatral").

2 Jorge Dubatti en Filosofía del teatro I utiliza el término "asistentes" para aludir tanto a los actores, que brindan su asistencia para que el acontecimiento se lleve a cabo, como a los espectadores, que asisten presencialmente al mismo. 
básica del código teatral propuesta por la investigadora alemana Erika Fischer-Lichte: "A representa a X mientras S lo mira" (99). Como veremos a lo largo del artículo, los conceptos tomados del psicoanálisis no sugieren una praxis psicoanalítica en el teatro, sino que se les adapta con el fin de utilizarlos para explicar la comunicación en el teatro.

Estas bases han sido elegidas dada su naturaleza sintética, esto nos permitirá operar los conceptos con la mayor claridad posible. El Grafo III, que es también conocido como el Grafo del neurótico, se sustenta en los estudios derivados del complejo de Edipo. Éste, por su parte, toma su nombre del análisis hecho por Freud para establecer la institución del sujeto psíquico, específicamente de la personalidad neurótica (como veremos, el sujeto trágico en la teoría del drama tiene estructura neurótica). La fórmula de Fischer-Lichte nos permitirá entonces hablar de dos sujetos neuróticos con una estructura topológicamente similar.

Se nos presenta también la necesidad de esclarecer nuestra postura técnica sobre la diferencia entre el personaje (en este caso desde un abordaje trágico) y el actor. Veremos que, con base en la Poética de Aristóteles, se habla de un actor asumiendo unas circunstancias hipotéticas dentro de tres unidades básicas: un espacio, un tiempo y unas acciones determinadas, sin olvidar que lo hace desde sí mismo, es decir, no "deja de ser él mismo para ser otro en el escenario", su constitución como sujeto psíquico es inalterable. El concepto de personaje, por lo tanto, es la conjunción de los rasgos (físicos y de carácter) que adopta el actor en la convención ficticia.

Del mismo modo, cabe aclarar que, aunque la discusión entre texto y representación abordada por Anne Ubersfeld en Semiótica teatral se hace presente al hablar de la relación entre psicoanálisis y teatro (ya que los primeros cruzamientos entre estas disciplinas surgieron del teatro como literatura), aquí no se pretende disertar ni disipar las claras diferencias entre éstos, sino dar soporte a la construcción de un modelo de comunicación, el cual ocurre durante la representación, a partir de la visión trágica que ofrece el drama como literatura en la tragedia griega, es decir, se considerará al teatro en ambas dimensiones para establecer el vínculo con el psicoanálisis.

Es en este punto donde analizamos la identificación, que en apariencia es con el discurso y proceder del personaje del texto, pero también a partir del tratamiento e interpretación que el actor es capaz de otorgarle (y otorgarse) a/en la vivencia del personaje. Tanto actores como espectadores se enfrentan a la vivencia de la realización de sus deseos no cumplidos, liberando así lo reprimido a través de la catarsis (aristotélica):

Aquí, la condición previa para que se dé el goce es que también el espectador sea un neurótico. En efecto, sólo a un neurótico podrá depararle placer la liberación y, en cierta medida, también la aceptación consciente de la motivación reprimida, en vez de despertar su repulsión, como ocurrirá con toda persona no neurótica (Freud 4). 
El presente estudio analiza la relación entre actor y espectador, acotados a la personalidad neurótica, que es la que se estructura en el personaje trágico. Estas condiciones, además de cimentar las bases de la investigación, develarán la vigencia del teatro trágico como inherente al ser humano.

\section{Sobre los cruzamientos entre psicoanálisis y teatro}

La relación entre teatro y psicoanálisis cuenta con una larga historia en ambas disciplinas. No debe extrañarnos que las aproximaciones del psicoanálisis a la psique humana encuentren tantas referencias en el teatro, específicamente en la tragedia, ya que el mismo Freud fundó pilares de su teoría en el análisis de célebres personajes trágicos: Edipo y Electra.

Ya desde los inicios de la tragedia griega nos encontramos con una figura de oficio curiosamente semejante al de la lectura psicoanalítica: el oráculo, que al escuchar el discurso de Edipo es capaz de advertir la mala fortuna de su familia, y "dictaminar" el destino fatal de Layo y la deshonra de Yocasta a manos de su hijo:

Pese a la desmentida de los padres adoptivos, Edipo decide consultar al oráculo de Delfos que pronuncia que matará al padre y se acostará con la madre. Para evitar que la maldición se cumpla, deja Corinto, pero en un altercado mata a Layo, sin saber que es su padre... [...] El paciente consulta al psicoanalista por vivir en una tragedia que se obstina, sin saberlo, en repetir. Así como Edipo, se rebela contra el destino marcado por el oráculo... (Wechsler 18).

Esta noción del destino fatal, presente en la tragedia griega y que es condición para que suceda la fórmula aristotélica de la catarsis, será fundamental para el psicoanálisis y el principio de la teoría de la repetición neurótica, donde Freud toma como héroe trágico moderno a Hamlet, quien, al enfrentarse con el cumplimiento de sus deseos reprimidos en la figura de su tío el usurpador Claudio, desarrolla un síntoma neurótico que le hará postergar la decisión de matar a Claudio, ya que esto supone su propia destrucción.

Más tarde, Lacan recurriría a Antígona de Sófocles para referir su trabajo sobre la ética del psicoanálisis y hablar de la pulsión de muerte: "Pero siniestra sería también la pasión que lleva a Antígona (es aquella que ya apunta hacia la muerte, dirá Lacan) a cruzar el límite de lo bello y entregarse a la pulsión de muerte" (Casanova 85). Actualmente, el director e investigador argentino Gustavo Geirola desarrolla su teoría de la Praxis teatral, fundamentándola en la relación entre teatro y psicoanálisis, operando conceptos psicoanalíticos sobre el ensayo teatral con una lectura lacaniana. 
INVESTIGACIÓNTEATRAL

Revista de artes escénicas y performatividad

Vol. 11, Núm. 18

octubre 2020-marzo 2021
La comunicación entre actor y espectador: una aproximación al psicoanálisis

Iván Zúñiga Vargas

\section{La comunicación en el teatro}

En lo que respecta a la comunicación teatral, directores como Konstantín Stanislavski, Peter Brook y Jerzy Grotowski, entre otros, hicieron énfasis en la importancia de asumir al teatro como un proceso de comunicación compleja; sin embargo, se ha realizado poca investigación al respecto. Autores como Manuel F. Vieites, que en "Teatro y comunicación" recopila algunas nociones al respecto, y Tadeusz Kowzan, que establece los trece signos teatrales, se han aproximado a la investigación del tema. Vieites plantea las posibilidades que surgen del estudio del teatro como comunicación, mientras Kowzan se dirige a los elementos semióticos del teatro.

Para adentrarnos en el terreno de la comunicación, hemos de acudir al modelo del lingüista Roman Jakobson, aunque existen modelos más complejos en lo que se refiere a la comunicación de medios masivos que pueden adaptarse más al acontecimiento teatral, dado el aparente rol pasivo del espectador. El origen saussureano del modelo de Jakobson nos atañe, precisamente, porque el Grafo III de Lacan también se desprende en un principio del modelo del signo de Saussure. Representado para nuestros fines de la siguiente manera:

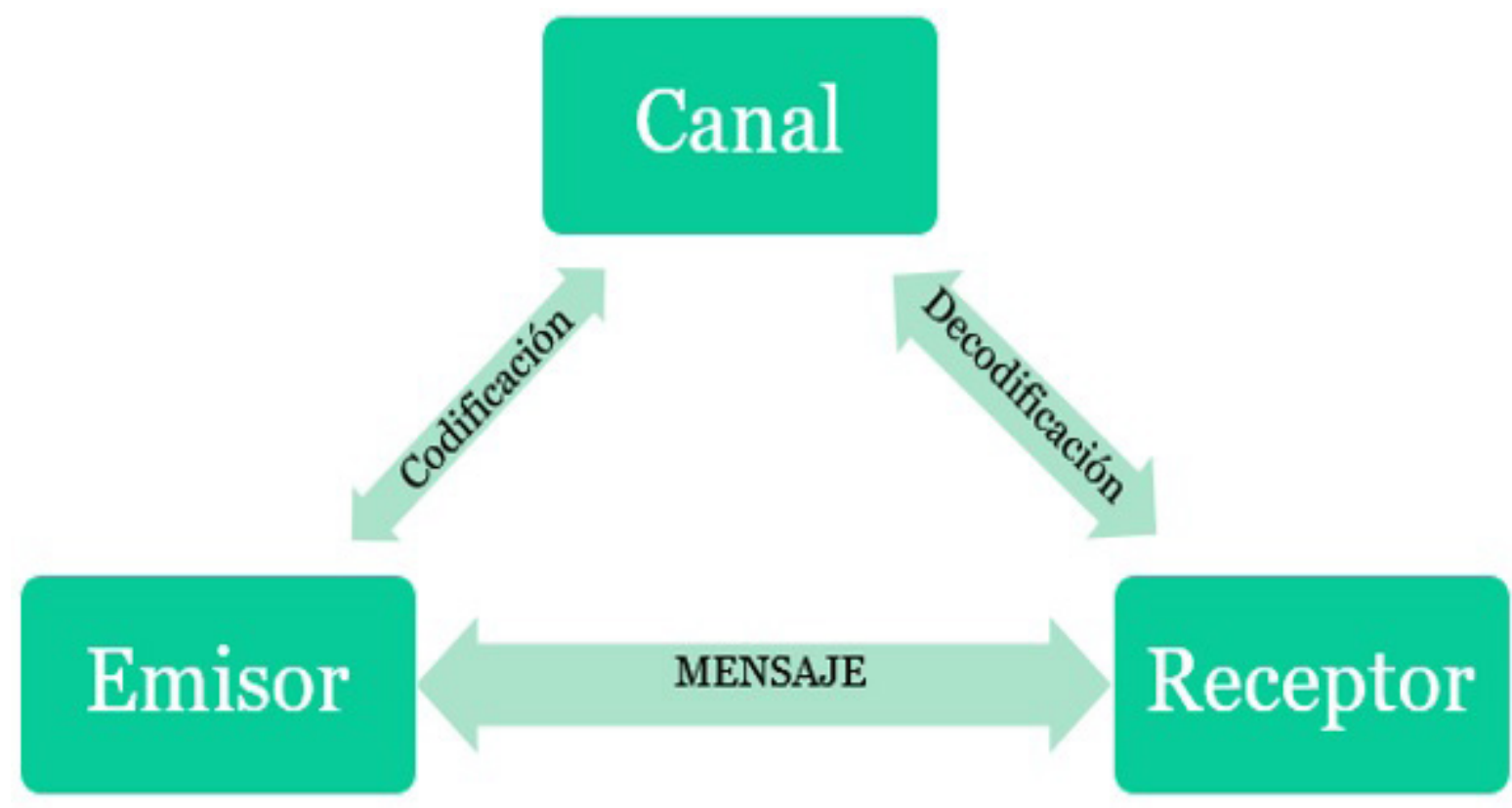

Modelo de comunicación de Jakobson. Elaboración propia. 
Según este esquema, la comunicación es un proceso de estímulo-respuesta entre interlocutores condicionados al conocimiento de un código, que se transmite a través de un canal definido. Su limitante radica en que el receptor cuenta con un papel activo y equiparable con el del emisor, y transportado al teatro, el espectador sería relegado a la pasividad de la pura recepción, imposibilitando la réplica y la participación en la producción de mensajes. Por otro lado, respecto a este modelo estaríamos obligados a colocar un emisor múltiple, ya que la construcción del aparato escénico (entiéndase el total de mecanismos materiales y conceptuales en la escena) proviene de un conjunto de creativos que intervienen para su concepción.

Efectivamente, se ha codificado un mensaje que se va a transmitir mediante el acontecimiento teatral, el cual va a ser leído y decodificado por el receptor (los espectadores que, como ya vimos, estarán imposibilitados para acreditar o confirmar el contenido del mensaje). Bajo este esquema se nos presenta la pregunta sobre si cabe hablar de comunicación teatral:

Sin embargo, Mounin, en Introducción a la semiología, trasladaba al campo de la investigación teatral cuestiones substantivas y dos casos para el estudio. En el capítulo titulado "La comunicación teatral", cuestionaba, en primer lugar, la posibilidad de hablar de "lenguajes" de la escena, para luego preguntar "si el espectáculo teatral es comunicación o no" (1972: 100, 101). A pesar de la provocación que suponía afirmar que en teatro no cabe hablar de comunicación, pocos estudios han intentado ir más allá de afirmar la dimensión comunicativa del teatro en la relación actor/espectador (Vieites 1155).

Bajo esta afirmación y utilizando la fórmula básica del código teatral, de Fischer-Lichte, comienzo a sentar la primera base respecto a la noción del personaje: hablamos de un actor que asume un rol dentro del juego dramático, al que corresponde un cierto carácter, una identidad ficticia. El personaje surge de la interpretación que hace el actor de estas características y circunstancias dadas, la cual partirá de sus propias posibilidades e historia, es decir, será resultado de una potencia de sí mismo:

\section{${ }^{X}(\mathbf{S})=(A)^{X}$}

Modelo de la comunicación teatral de Fischer-Lichte. Elaboración propia.

A (actor) representa a X (personaje), mientras S (espectador) lo mira (Fischer-Lichte), graficado de esta manera para fines explicativos, donde $\mathrm{X}$ es potencia de A como bien podría serlo de $\mathrm{S}$ y éstos ocupan una posición semejante frente a tal potencia. 
Si bien, hablar de la comunicación en el teatro nos coloca frente a un abismo de complejidades, es aquí donde el psicoanálisis ofrece un soporte. Para Lacan, el significante se desprende de la concepción saussureana que tanto ha prevalecido en la teoría teatral: la noción del signo como la correspondencia entre un significado y un significante, para convertirse en una entidad autónoma que logra un sentido a partir de situarse como eslabón de una cadena hecha de significantes. "Esto le permite a Lacan pensar la cadena significante como diciendo incluso más de lo que se quiere decir, y hasta diciendo incluso otra cosa de lo que se quiere decir" (Geirola 5).

Para fundamentar esta postura, parafraseo a Manuel Asensi cuando habla del discurso del Otro -que aquí es articulación inconsciente de significantes- en la teoría lacaniana, con un ejemplo simple: es común pensar que cuando yo leo una novela estoy leyendo al autor; sin embargo, la sanción que ese mensaje recibe de mi propio código al momento de la lectura implica que, de hecho, estoy leyendo a ese otro ubicado en mi propio inconsciente y, si vamos más allá, el mismo autor escribe más que de lo que es consciente.

Esto colocaría al actor y al espectador en el mismo plano de "lectura" del personaje. Si ambos acuden al texto, ocurre lo dicho por Freud en "Personajes psicopáticos en el teatro": aunque en el poema épico resulta mucho más fácil la identificación con el héroe, en la representación se apuesta por la modificación emocional que provoque en el espectador el terror y la compasión. Aquí se nos presenta la separación entre texto y representación: el actor va a comunicar aquello que dejó de ser texto para ser actuación, y lo va a comunicar a través de sí mismo dentro de la convención ficcional, es decir, encarnará las acciones trágicas: transgrediendo la ley y la voluntad divina hacia el cumplimiento de sus deseos (a lo que el espectador reaccionará con terror por el castigo que sabe que aquello supone) para desencadenar su destrucción (provocando, así, la compasión en el espectador).

Aquí, la visión trágica es indispensable, pues la efectividad del mensaje estará ligada a la estructura dramática. Retornando así al acontecimiento del lenguaje, ya que efectivamente sucede en una representación desprendida de un texto, por medio de la transmisión de la palabra y de la situación anecdótica definida por el (los) dramaturgo(s), quienes aportan su interpretación en el proceso creativo y diseñan la lectura que se pretende ofrecer al espectador.

En su teoría de la praxis teatral, Geirola nos habla en primer lugar de distintas dramaturgias: de autor, de director, de actor y creación colectiva; y en segunda, de máscaras espectatoriales como la posibilidad de producir un diseño psicótico, perverso o neurótico para la visión del espectador. Como se advirtió en un principio, el presente acercamiento parte del supuesto de un espectador neurótico.

Recapitulemos lo enunciado hasta aquí para concretar las bases del modelo en cuestión: Existe un acontecimiento teatral entendido en sus tres momentos: (a) convivial, en tanto que requiere la asistencia (presencia y colaboración) de un ejecutante y un espectador; (b) de len- 
guaje, debido a la emergencia de la palabra (que no depende de su pura enunciación fonética, sino de su colocación en la cadena significante), aquí juega el registro simbólico, en la posibilidad de estructurar mediante el lenguaje. Y (c) acontecimiento de la constitución del espacio del espectador, en tanto se diseña la visión del receptor. Es indispensable entender el lenguaje no como la mera enunciación de palabras, sino como una estructura de interpretación. Por ejemplo, en el "teatro sin palabras" éstas no se emiten vocalmente, pero el registro simbólico se estructura y encuentra lógica consciente a través de palabras, es decir, el actor desarrolla sus acciones a partir de un discurso previamente ensayado, el espectador "lee" dicha acción y pone en palabras aquello que interpreta a partir de ello.

El receptor se convierte en algo más que un espectador pasivo, ya sea que acuda a un teatro "participativo" o a un montaje realizado con convención de la cuarta pared. La lectura espectatorial responde de un modo u otro al mensaje que se le ofrece, participa en la comunicación desde el momento en que asiste y se coloca ante un hecho escénico, disponiendo (consciente e inconscientemente) sus propias emociones al seguimiento del héroe. La identificación que experimenta el espectador es una aspiración que surge de la necesidad de ser protagonista de su propia vida, con la seguridad de resultar ileso y abriendo así paso al placer (que deviene en placer estético).

\section{El personaje trágico, la visión trágica y su encuentro con el sujeto trágico}

La estructura del personaje trágico, según la teoría de los géneros de Luisa Josefina Hernández, nos presenta al héroe como un individuo lleno de virtudes y con un defecto que lo llevará a tomar una decisión trágica. Es este rasgo el que desemboca en su destrucción, ya que, tal como le sucede a Aquiles, una insignificante grieta es la que vulnera toda la estructura.

Hablamos de un personaje complejo, aunque aquí no existe una relación con los motivos inconscientes ni se habla de la voluntad del personaje sino de destino, de decreto universal y de una coacción divina. Al mirar esta estructura desde el psicoanálisis, veremos que se trata del reino del significante, pues su motivación (la del personaje) surge de una carencia que produce una necesidad y ésta a su vez se encarna en una demanda. Demanda que no alcanzará a suplir la necesidad; es esta operación la que dejará como resultado un deseo de algo que el héroe no posee (y no puede poseer), que lo llevará a tomar decisiones, equívocas o no, ya que en palabras de Lacan: "nuestros actos fallidos son actos que triunfan” (386), para finalmente alcanzar su propia destrucción. Esta condición permite al actor asumir las acciones del personaje desde su ser psicológico (no psicologizando al personaje, sino a través del tránsito vivencial por los estados de decisión). 
En la tragedia, es la destrucción lo que restaura el orden universal (social), según lo instituido por los dioses. Aquí se hace presente la extensión de la visión trágica hacia la comedia, ya que ésta - pese a tener una estructura aparentemente inversa con un héroe colmado de vicios y defectos, pero con una sola virtud- tomará un sesgo trágico al desencadenar en el ridículo de aquél, en su exposición frente a la muchedumbre, reafirmando también la escala de valores instituida por la sociedad. Vemos entonces que la visión trágica está separada de la tragedia como género literario, y que ésta se concibe en los principios de dualidad y ambivalencia como motor de las acciones humanas.

La figura del héroe trágico supone que se trata necesariamente de un individuo digno de la admiración del clan al que pertenece, elevado, ejemplar y respetable, lo que le otorga un estatus y una imagen social superior. Este rasgo constituye, en la identificación, la percepción de sí mismo del espectador, cuya imagen de honor y dignidad se ha construido a partir de reprimir aquellos deseos que no quiere reconocer.

El sujeto trágico del psicoanálisis lacaniano está constituido por tres registros que se entrelazan: (a) el registro imaginario que se instaura en el estadio del espejo, la imagen del yo formada por el reflejo del otro, de condición abstracta donde se ubica la percepción; (b) el registro simbólico, donde se le da estructura a lo imaginario y donde se ubica el lenguaje pero también la Ley (el terreno del significante), y (c) el registro de lo real, que es inalcanzable pero fáctico, en el sentido de que no se le puede asignar un fonema o una representación porque es el objeto mismo (al asignarle una representación pasará al registro imaginario o al simbólico). En la intersección de estos tres registros se encuentra el objeto $a$, objeto del deseo que no alcanza su realización.

Es precisamente en la institución de estos tres registros, según Lacan, donde se origina la falta, esa carencia que lleva al sujeto a emprender acciones en busca de la completud. Es importante aquí advertir la represión original que inaugura el inconsciente: el complejo de Edipo se establece con la aparición de la Ley del padre, es decir, cuando el padre interviene para declarar la prohibición de la relación incestuosa con la madre que, si bien en algún momento sí que es genital, no supone el total del fenómeno libidinal por aquel primer Otro que es la madre, quien trae el lenguaje y lo transmite; por ello, se entiende que el lenguaje precede al sujeto:

Freud concibe por tanto el inconsciente como una memoria de huellas que insisten entre la percepción y la conciencia, lugar donde Lacan sitúa al Otro del inconsciente. El inconsciente por tanto conforma un saber que no se sabe, un saber que no está a disposición del sujeto y que, sin embargo, va a dar marco a su deseo y a sus modos de satisfacción. El inconsciente se estructura como una serie de represiones atraídas por un primer núcleo que constituye la represión original (Gonzales párr. 15). 
Dichas represiones van a dialogar de manera permanente con el discurso del sujeto, o más bien a irrumpir con éste, de modo que para el psicoanálisis los sesgos en el discurso son aquellas grietas que dejan entrever lo que se dice detrás de lo que se cree que se dice. A pesar de ser una teoría para la clínica psicoanalítica, conviene preguntar: ¿Estas estructuras son expuestas cuando alguien se coloca como espectador de un hecho teatral? Ante la exaltación de las emociones y al presenciar de manera directa la ruptura de la ley, ¿cuánto de lo que el espectador no dice se revela (a sí mismo o al acontecimiento)?

[...] aunque no cabe duda de que se trata de un encuentro con lo real, en el sujeto neurótico éste va a estar necesariamente modulado, filtrado, paliado, y en directa relación con las huellas inconscientes de cada cual, que van a imprimirle diferente significación. El peligro exterior estará en el neurótico en íntima relación con el peligro interior (Gonzales párr. 20).

\section{De la necesidad a la repetición inconsciente y la imagen del yo}

En este punto se hace necesaria la presentación del Grafo iII de Lacan, que será el que servirá de soporte ante estos cuestionamientos. Cabe reiterar lo acotado en un principio: no se trata de llevar la clínica psicoanalítica al acontecimiento teatral y revelar en el actor y el espectador aquello que sólo puede ser alcanzado mediante el análisis; el objetivo aquí es más bien tomar de la teoría psicoanalítica sobre el inconsciente aquellos conceptos que, adaptados, permitan operar en la consideración de la comunicación en el teatro. Geirola advierte, en sus notas introductorias a la Praxis teatral, que, más que buscar un rigor científico de comprobación o demostración, el terreno del psicoanálisis es de carácter conjetural.

A partir de los conceptos que constituyen al Grafo III de Lacan, ${ }^{3}$ y antes de seleccionar algunos arbitrariamente, es necesario seguir planteando preguntas: ¿Por qué, si el sujeto de la necesidad se nos presenta como anulado en esa misma necesidad, insiste en la articulación de una demanda? ¿Es porque, debido a la Ley, no puede, por sus propios medios corporales, suplir esa necesidad? Si el deseo que ha resultado de la sanción del Otro va a permanecer en falta (dada la imposibilidad de ser significado), ¿qué efecto tiene la repetición inconsciente? ¿Es acaso la metaforización de ese significante la que finalmente se comunica en un mensaje

3 Ver imagen del Grafo II en la pág. 69 de Una introducción a Lacan (D'Angelo, Carbajal y Marchilli), disponible en: www.academia.edu/34860359/Una_introducci\%C3\%B3n_a_Lacan_Eduardo_Carbajal_Rinty_DAngelo_and_Alberto_Marchilli. 
otro cifrado? Entre la imposibilidad de comunicar el saber inconsciente y la exigencia consciente de una producción de sentido, ¿el sujeto encuentra un modo de suplir su necesidad?

Es precisamente en la concepción trágica del sujeto que encontramos respuesta a estas preguntas, un modo de relacionar a X con A y con S. Si miramos en perspectiva ya no el grafo ni el modelo, sino las implicaciones pragmáticas de la condición del sujeto, veremos incluso que la concepción del destino está implícita en la repetición inconsciente, y que los dioses tienen estructura del deseo articulado con el significante.

\section{La otra comunicación en el teatro o la comunicación del Otro en el teatro}

Si partimos del supuesto de que la producción de sentido que nos permite la comunicación mediante un discurso corriente - uno donde entendemos y somos entendidos, donde operan los esquemas tradicionales de comunicación- es tan sólo el piso inferior que se sostiene en la consciencia del sujeto, y que a éste se le superpone un piso superior que le estructura y condiciona, comprenderemos la necesidad de un modelo más complejo, si es que cabe hablar de la transmisión de un mensaje otro.

Al retornar ahora a la noción de comunicación vista anteriormente en el modelo de Jakobson, lo que queda de manifiesto no es ya su incompatibilidad para definir la comunicación en el acontecimiento teatral, sino el que ofrece un punto de partida (una vez entendido el origen del fenómeno en relación con la articulación de significantes). Siguiendo a Dubatti, el acontecimiento va a conformar el canal, constituido en sus tres momentos (el convivio, la palabra y la constitución del espacio del espectador), como medio de transporte del mensaje. Híbrido, compuesto de materia viviente y de objetos transfigurados, efímero por naturaleza - pues cuenta con un momento de inicio y un final del enlace-, así, cuando sucede permite la comunicación; es el terreno convencional del teatro como lugar de donde se mira.

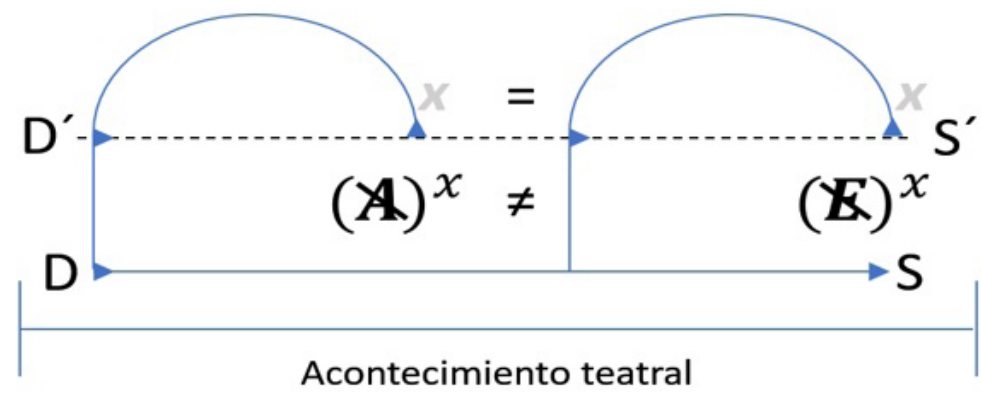

Modelo de comunicación teatral. Elaboración propia. 
Se presenta el modelo sugerido y a continuación una explicación detallada de los elementos incluidos, tanto la adaptación como la síntesis de los momentos surgen de la necesidad de concretar un modelo de comunicación, de identificar los puntos de encuentro apegados a la teoría lacaniana y no de una intención de reinterpretarla. Con la finalidad de diferenciar claramente los elementos del modelo sobre la representación del actor y del espectador, antes marcados en la fórmula de Fischer-Lichte como (A) actor y (S) espectador, este último pasará a ser representado ahora con (E) y el personaje continuará con la letra $(\mathrm{x})$.

Esto es: Un actor (A) interpreta a un personaje $\mathrm{e}^{\mathrm{x}}$, generando un sentido a nivel consciente $\underline{\mathrm{DS}}$, mientras que un espectador (E) reinterpreta al personaje $\mathrm{e}^{\mathrm{x}}$, continuando con la generación de sentido (mensaje) DS. Al mismo tiempo, a nivel inconsciente ambos se han encontrado con la imposibilidad de significar algo del personaje $\mathrm{e}^{\mathrm{x}}$ a partir de la cadena significante superior, falta que desencadena una repetición inconsciente $\underline{D^{\prime}} \mathrm{S}^{\prime}$, que va a tener consecuencias en la producción de sentido.

Entenderemos que, en la función $(\mathbb{A})^{x}$, así como en $(\mathbb{E})^{x}$, al haberse significado al personaje como una potencia (posibilidad, identificación) tanto del actor como del espectador (respectivamente), y en tanto que éstos se presentan anulados en su necesidad (por ello están barrados), ya se contempla lo que en el grafo de Lacan es el tránsito de la necesidad por la demanda hacia la sanción del código, resultando en la exigida significación a través de la diacronía del significante; ésta se representa en el tránsito DS.

Como se ha establecido, este nivel se encuentra en el terreno de la semiosis y de la lingüística, la transmisión de un mensaje a través de un canal (acontecimiento) y por un código (signos teatrales) determinados. Desde luego, la producción de un sentido en $\underline{\mathrm{DS}}$, pese al acuse de recibo que puede otorgar el receptor, se encuentra subordinada a la interpretación de cada una de las partes, es decir, al entendimiento del personaje y del constructo escénico a nivel consciente. $Y$ es totalmente dependiente de la coincidencia de conocimientos y herramientas con las que cuente, por un lado, el actor y, por otro, el espectador. Esta no igualdad ha sido significada al centro de este nivel como " $\neq$ ”.

$\mathrm{Al}$ incluir el desdoblamiento hacia el inconsciente, la intención es precisamente ir más allá de aquello que ya ha sido expresado como una dimensión comunicativa en el teatro. Si bien esta propuesta puede parecer limitada por ahora, se mantiene en la exploración del origen trágico del teatro. El sujeto barrado indica que en la demanda va implícita una necesidad doble: la relativa a la intención consciente de comunicar algo y la necesidad de completud, aquella que fracasa en cada intento.

De la operación simultánea por generar un sentido resulta una falta de significante (esto se representa con "velada), poniendo en operación ese "saber que no se sabe" y que, dada la repetición en busca de significarse, irá surtiendo efectos en la conducta de los 
asistentes. Es aquí donde se propone hablar de una comunicación otra, producto de la actividad de los mecanismos inconscientes tanto del actor como del espectador.

Aquí es donde cobra su verdadera importancia la condicionante del personaje trágico. Si bien -como ya se ha acotado- podría no tratarse necesariamente del protagonista de una tragedia en tanto género literario, sí hablamos siempre de un personaje construido según una visión trágica, un héroe de "condiciones semejantes" a las del sujeto trágico del psicoanálisis.

Es en la identificación con el personaje trágico -donde se presenta la posibilidad de encontrarse a sí mismo como su reflejo- que el actor ha emprendido la tarea de asumir realmente las circunstancias de la ficción, la que se presenta como dominada por quienes convienen en darle sustancia. El espectador va a ir descubriendo en la trama la posibilidad de identificarse con el actor que ha asumido ese rol trágico, y se dispondrá, como el niño que imagina ser aquel adulto, capaz de acciones poderosas, a prestar su capacidad emotiva al seguimiento del héroe. Pero es en la revelación de las grietas en la idealización de este héroe, donde se hace presente la catarsis.

Por tanto, tenemos que en el dominio del Otro se estructura tanto un mensaje que produce sentido, como también los lapsus que atraviesa el actor a causa de la repetición inconsciente. Hay, en el modelo, un vaivén en tanto cadenas significantes que se concatenan de la interpretación del actor a la reinterpretación del espectador. Es aquí donde se produce una comunicación que, aunque inconsciente, sucede y repercute en la articulación de significantes, aquello que no se llega a articular en la producción de sentido estará relacionando a los asistentes del acontecimiento.

El Otro (que en la cotidianidad muchas veces juega en contra del sujeto) al implicarse como sustrato de la acción del actor-personaje, es potencialmente sustantivo y le provee de una estructura compleja desprendida de las experiencias y formaciones inconscientes del sujeto. Sin embargo, ante la imposibilidad de disponer a voluntad de acceso a este terreno, se presenta la posibilidad de activar mecanismos de defensa como la cohibición.

\section{Conclusiones}

Este trabajo es una propuesta de aproximación para representar la comunicación teatral desde su naturaleza compleja, dejando ver que hay más que una lectura semiótica, más que una supuesta interpretación de signos diseñados circularmente. Al introducir la noción del inconsciente se establece la existencia de grietas en la interpretación que, si bien escapan al entendimiento consciente, se encuentran ahí, en otro terreno, operando a través del sujeto. 
Pretendemos provocar el interés por visualizar al teatro desde otras perspectivas, aunque el resultado incurre en inferencias de conocimiento previo. Quizá se deba aclarar que se trata de un primer intento para establecer el diálogo sobre la existencia de lazos inconscientes creados durante el acontecimiento teatral. El trabajo posterior será entonces indagar si el modelo es funcional y cuáles son los ajustes esenciales que requiere. Para trasladar el modelo presupuesto a una fase de experimentación, sería necesario un complejo estudio de caso donde, tanto un actor como un espectador (ambos analizantes y asistentes de un mismo acontecimiento teatral con las características antes establecidas), estuvieran dispuestos a transitar el recorrido y compartir los resultados.

En el camino por estructurar esta propuesta se revelaron algunas carencias de claridad y áreas a explorar, como una comprensión acaso básica de los conceptos lacanianos. Esto que nos permitió el proceso inductivo para la generación del modelo, también es una limitante en cuanto nos acercamos a la complejidad de la teoría psicoanalítica. Sin embargo, acotar la operación a la fórmula trágica y su relación con los preceptos aristotélicos permitió el cruzamiento de las nociones sobre el personaje, dada su construcción a partir del actor y la relación directa que tiene el espectador con ésta. Quizá no habría que hablar de identidades sino de construcciones psicosociales, lo que nos llevaría de cierto modo a explorar esta relación desde la antropología y la psicología social. La práctica teatral contemporánea exige cada vez más estudios transdisciplinarios que den cuenta de las dimensiones que alcanza, aunque queda mucho por explorar en relación con otros campos. El 'eterno retorno' al origen trágico tiene su sitio en los círculos de investigación.

El psicoanálisis y su implicación con el teatro permitirá, en tanto se investigue esta relación, acceder a teorías que nos alejen de la subjetividad y del empirismo que tanto ha prevalecido entre el gremio, así como formar teatristas conscientes de los alcances de su actividad. Éste ha sido el objetivo del presente trabajo, para el cual fue imprescindible la observación como método de recopilación de datos, tanto como la documentación teórica. Estos aspectos permitieron establecer los vínculos entre ambas disciplinas.

La investigación desde una perspectiva transdisciplinaria, más allá de desdibujar las líneas que establecen los campos de estudio, es una invitación a expandirlos, relacionando conocimientos de distintas áreas con la oportunidad de potenciar los alcances de cada una.

\section{Fuentes consultadas}

Casanova, Basilio. "Lacan y la esencia de Antígona”. Trama y fondo: revista de cultura, núm. 15, 2003, pp. 83-94. dialnet.unirioja.es/descarga/articulo/803851.pdf, consultado el 13 de octubre de 2020. 
Wechsler, Elina. Psicoanálisis en la tragedia. De las tragedias neuróticas al drama universal. Madrid: Biblioteca nueva, 2001.

Asensi, Manuel. "Lacan para multitudes: Primera sesión". Conferencia por YouTube, subido por MACBA Barcelona, 3 de julio de 2014, www.youtube.com/watch?v=4i2vQEHnpEs\&t=3s, consultado el 13 de octubre de 2020.

Asensi, Manuel. "Día 1: Sesión sobre Lacan y el deseo”. Conferencia por YouTube, subido por Manuel Asensi Pérez, 14 de noviembre de 2016, www.youtube.com/watch?v=GMAmXwjw4E4\&ab_channel=ManuelAsensiP\%C3\%A9rez, consultado el 13 de octubre de 2020.

D’Angelo, Rinty, Eduardo Carbajal y Alberto Marchillí. Una introducción a Lacan. Buenos Aires: Lugar Editorial, 1986.

Dubatti, Jorge. "Cultura teatral y convivio". Conjunto, núm. 136, 2005, pp. 88-96, www.casa. co.cu/publicaciones/revistaconjunto/136/dubatti.htm, consultado el 13 de octubre de 2020.

Fischer-Lichte, Erika. Estética de lo performativo. Soria: Abada Editores, 2013.

Fischer-Lichte, Erika. Semiótica del teatro. Madrid: Arco Libros, 1999.

Freud, Sigmund. "Personajes psicopáticos en el teatro". Biblioteca virtual universal, Bibliotecas rurales argentinas, 2010, biblioteca.org.ar/libros/211791.pdf, consultado el 13 de octubre de 2020.

Geirola, Gustavo. "Los cuatro discursos lacanianos y las dramaturgias”. Argus-a, vol.1, núm. 2, 2011. www.argus-a.com.ar/archivos-dinamicas/195-1.pdf, consultado el 13 de octubre de 2020.

Gonzales, Nieves. "Estructura simbólica y dimensión real: las neurosis". Colegio de psicoanálisis. Colegio de Psicoanálisis de Madrid, 15 de junio de 2017, colegiodepsicoanalisisdemadrid.es/estructura-simbolica-y-dimension-real-las-neurosis/, consultado el 13 de octubre de 2020.

Lacan, Jacques. Seminario I. Los estudios técnicos de Freud. Buenos Aires: Paidós, 1953.

Vieites, Manuel F. “Teatro y comunicación, un enfoque teórico”. Signa: Revista de la Asociación Española de Semiótica, núm. 25, 2016, pp. 1153-1178, www.cervantesvirtual. com/obra/teatro-4/, consultado el 13 de octubre de 2020. 